Fast transport from Southeast Asia boundary layer sources to Northern Europe: rapid uplift in typhoons and eastward eddy shedding of the Asian monsoon anticyclone

B. Vogel et al.

Correspondence to: B. Vogel (b.vogel@fz-juelich.de) 


\title{
Fast transport from Southeast Asia boundary layer sources to Northern Europe: Rapid uplift in typhoons and eastward eddy shedding of the Asian monsoon anticyclone
}

\author{
B. Vogel ${ }^{1}$, G. Günther ${ }^{1}$, R. Müller ${ }^{1}$, J.-U. Grooß ${ }^{1}$, P. Hoor ${ }^{2}$, M. Krämer ${ }^{1}$, S. Müller ${ }^{2}$, A. Zahn ${ }^{3}$, and M. Riese ${ }^{1}$ \\ ${ }^{1}$ Forschungszentrum Jülich, Institute of Energy and Climate Research - Stratosphere (IEK-7), Jülich, Germany \\ ${ }^{2}$ Institute for Atmospheric Physics, University of Mainz, Mainz, Germany \\ ${ }^{3}$ Institute for Meteorology and Climate Research, Karlsruhe Institute of Technology, Karlsruhe, Germany \\ Correspondence to: Bärbel Vogel \\ (b.vogel@fz-juelich.de)
}

\section{Supplementary material}

\subsection{0 days backward trajectories}

40-day backward trajectories starting at the observation along the flight path (every 10 seconds) on 26 September

52012 and ending at the origin of the air masses in the past (17 August 2012) are calculated. The potential temperature at the air mass origin $\left(\Theta_{\text {org }}\right)$ provides information about the vertical transport of the air mass along the trajectory. Transport pathways of air masses originating in intervals for $\Theta_{\text {org }}$

shown in Figures 1 and 2

Most air masses originate at $\Theta_{\text {org }}$ values between $360 \mathrm{~K}$ and $370 \mathrm{~K}$ (Fig. 1) occurred a moderately rapid uplift with mean values of about $2 \mathrm{~K} /$ day $(=22 \mathrm{hPa} /$ day) roughly in the region of the Asian monsoon anticyclone. Most of these air masses originate mainly in North Africa, South Asia, and in the West Pacific. The trajectories are also separated from the anticyclone approximately 8-14 days before the flight on 26 September 2012, and therefore transport air masses from inside the Asian monsoon anticyclone to Northern Europe.

At levels above, for $\Theta_{\text {org }}$ between $370 \mathrm{~K}$ and $380 \mathrm{~K}$ (Fig. 1), the trajectories are affected by both the Asian monsoon anticyclone and the subtropical westerly jet. The moderate uplift along the trajectories amounts to in average $1 \mathrm{~K} /$ day  gions around the Asian monsoon anticyclone and in Central America. In the latter case, the trajectories are most likely affected by the North American monsoon.

Most air masses originate at $\Theta_{\text {org }}$ between $380 \mathrm{~K}$ and patterns with a descent of air masses in the northern lower stratosphere. These trajectories do not circulate around the Asian monsoon anticyclone (except for two trajectories) and the air mass origins are spread throughout in the northern extratropical stratosphere, excluding regions affected by the Asian monsoon anticyclone such as South Asia or parts of North Africa. 

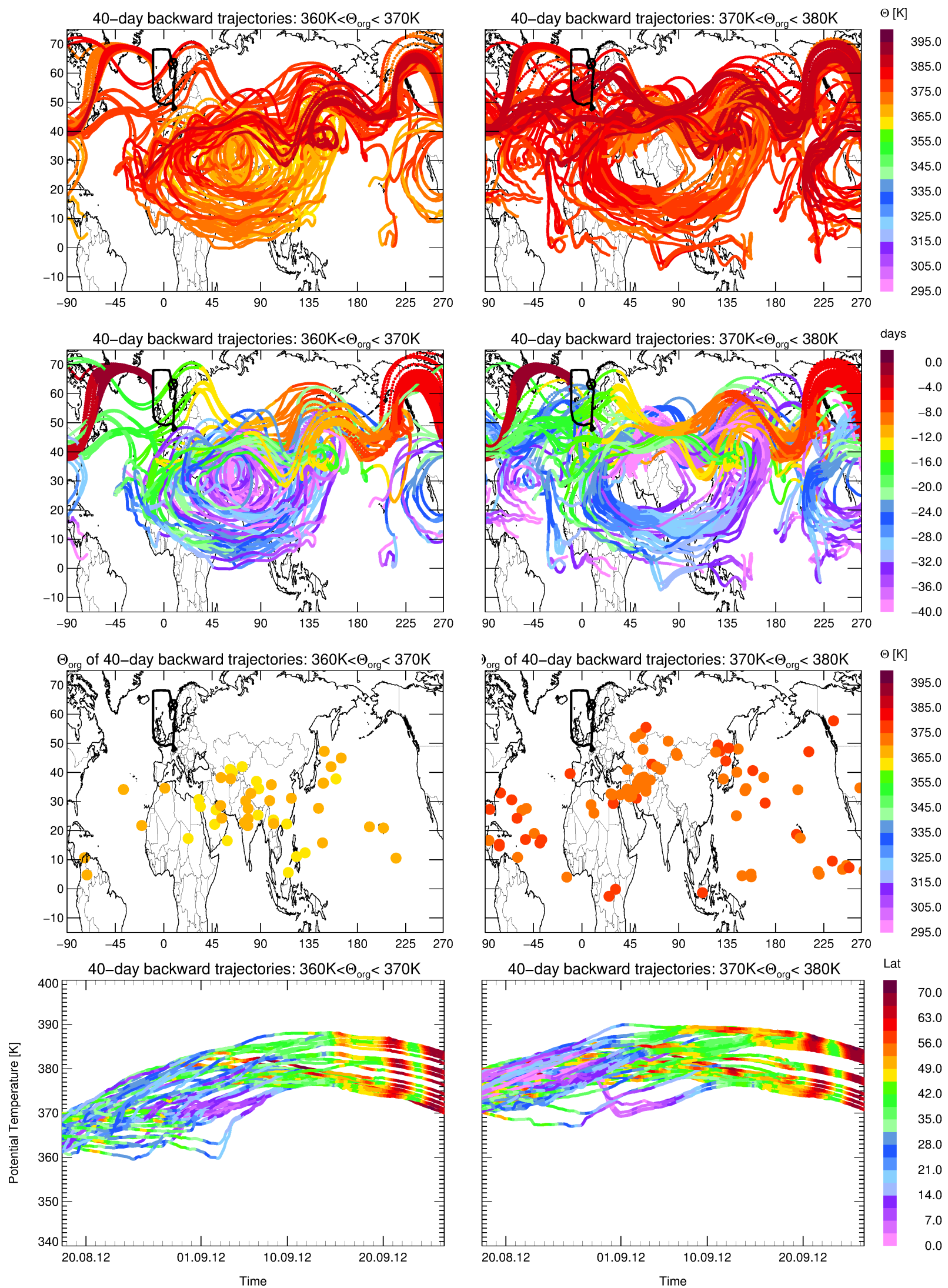

Fig. 1. Different 40-day backward trajectories for $\Theta_{\text {org }}$ intervals $360 \mathrm{~K}-370 \mathrm{~K}$ (left) and $370 \mathrm{~K}-380 \mathrm{~K}$ (right) are shown colour-coded by potential temperature (top) and by days reversed from 26 September 2012 (2nd row). Further, the geographical position of the origin of the 40-day backward trajectories ( $\Theta_{\text {org }}$ ) (3rd row) and potential temperature versus time along 40-days backward trajectories (bottom) are shown. Here, the colour indicate the latitude position of the trajectories. 

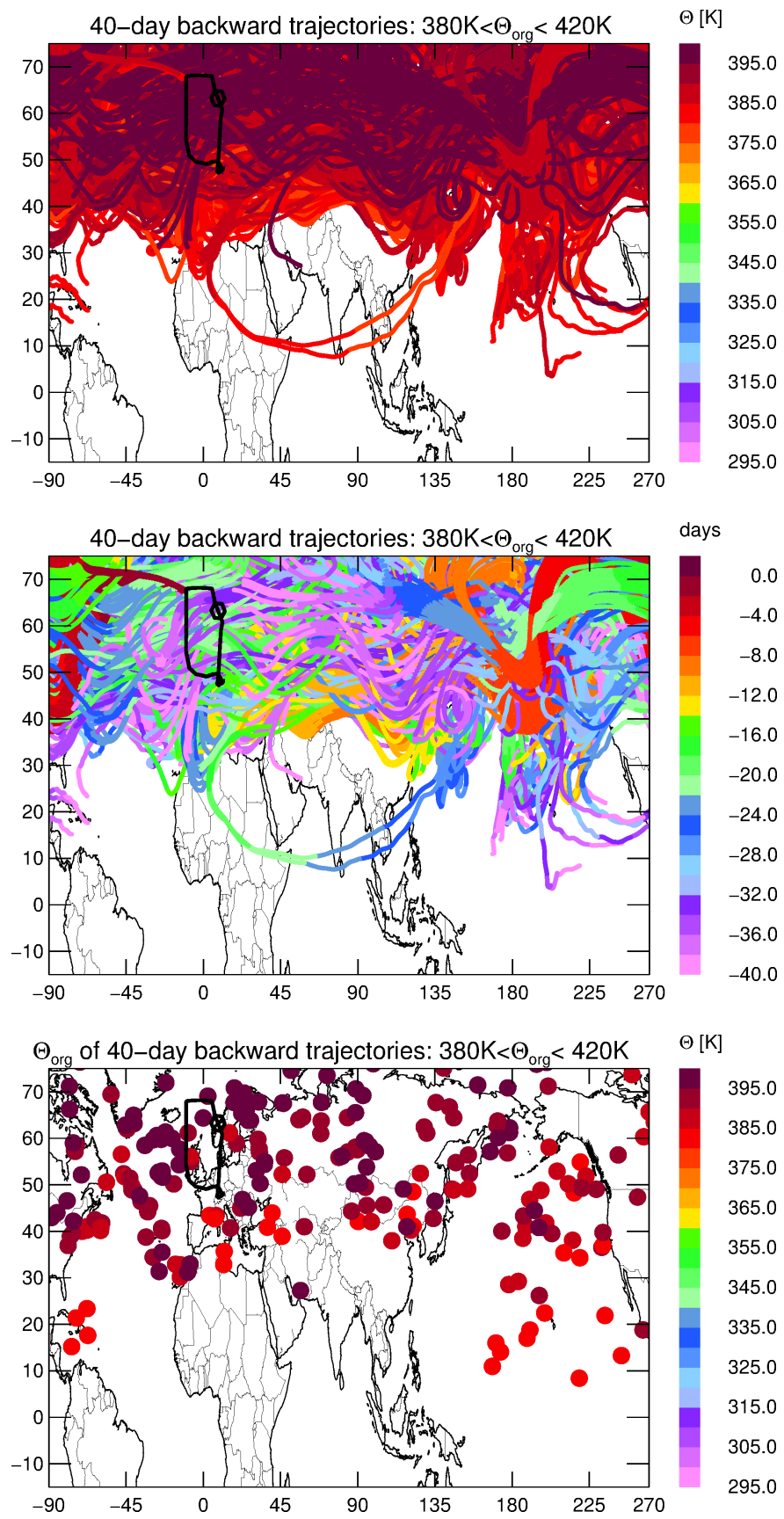

$\Theta[K]$

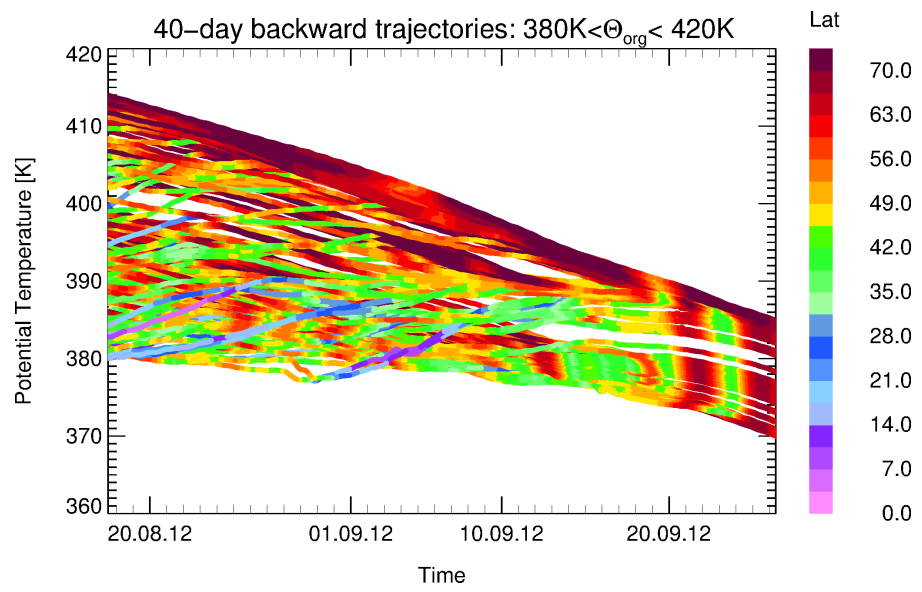

Fig. 2. Same as figure 1, but for $\Theta_{\text {org }}$ interval $380 \mathrm{~K}-420 \mathrm{~K}$. 